\title{
Neuromuscular blockade does not change the incidence or severity of pharyngolaryngeal dis- comfort after LMA anesthesia
}

\author{
[Le blocage neuromusculaire ne modifie pas l'incidence ou la sépérité de \\ l'inconfort pharyngo-laryngé après l'anesthésie avec un $M L]$
}

Thomas M. Hemmerling MD DEAA, ${ }^{*}$ Pierre Beaulieu MD PhD, ${ }^{*}$ Klaus E. Jacobi MD, $†$ Denis Babin MSc, ${ }^{*}$ Joachim Schmidt MD†

Purpose: Positive pressure ventilation using a laryngeal mask airway (LMA) has gained increased popularity. This study examined the influence of neuromuscular blockade on the incidence and severity of pharyngolaryngeal discomfort after positive pressure ventilation using a LMA.

Methods: 130 patients were included in this prospective, doubleblind, randomized two-centre study. Anesthesia was induced with remifentanil and propofol and maintained using remifentanil and sevoflurane in $30 \%$ oxygen and $70 \%$ air. Patients were mechanically ventilated at 15 breaths $\cdot \mathrm{min}^{-1}$ with tidal volumes to maintain $\mathrm{PETCO}_{2} 30-40 \mathrm{mmHg}$. Patients were randomly assigned to receive no neuromuscular blocking agent (NOBLOCK group) or cisatracurium prior to LMA insertion (BLOCK group). Prior to the end of surgery, morphine 3 to $5 \mathrm{mg}$ iv were injected. The ease of insertion of the LMA, cuff pressure, and inspiratory pressure were recorded. Patients were asked immediately after two hours, and $24 \mathrm{hr}$ after surgery to rate sore throat, dysphonia, or dysphagia as absent, minimal, moderate or severe. Continuous and categorical data were compared using t test and Chi-squared test, respectively.

Results: 68 and 62 patients were randomized to the NOBLOCK and BLOCK groups, respectively. Successful insertion on first attempt were $89 \%$ and $92 \%$ in the NOBLOCK and BLOCK groups, respectively. Mean intracuff and inspiratory pressures were $85 \pm 35 \mathrm{mmHg}$ and $13 \pm 3 \mathrm{mmHg}$ for the NOBLOCK group, and $96 \pm 34 \mathrm{mmHg}$ and $15 \pm 2 \mathrm{mmHg}$ for the BLOCK group. The immediate, two and $24 \mathrm{hr}$ postoperative incidences and severity of sore throat, dysphonia, and dysphagia did not differ significantly between the two groups.
Conclusion: Neuromuscular blockade does not influence the ease or rate of success of LMA insertion nor the incidence and severity of pharyngolaryngeal discomfort after positive pressure ventilation using a LMA.

Objectif : La ventilation à pression positive avec masque laryngé (ML) est de plus en plus populaire. Nous voulions vérifier l'influence du bloc neuromusculaire sur l'incidence et la sévérité de l'inconfort pharyngolaryngé suivant l'utilisation de la ventilation à pression positive avec un $M L$

Méthode : Notre étude prospective, randomisée et à double insu concernait 130 patients de deux centres. L'anesthésie, induite avec du rémifentanil et du propofol, a été maintenue avec du rémifentanil et du sévoflurane dans $30 \%$ d'oxygène et $70 \%$ d'air. Les patients ont été ventilés mécaniquement à raison de 15 respirations $\cdot \mathrm{min}^{-1}$ et des volumes courants permettant de maintenir la $\mathrm{PetCO}_{2}$ à 30-40 $\mathrm{mmHg}$. Ils ont été randomisés dans un groupe sans blocage neuromusculaire (NOBLOCK) ou avec bloc au cisatracurium administré avant l'insertion du ML (BLOCK). Avant la fin de l'opération, de 3 à 5 mg de morphine iv ont été injectés. La facilité de l'insertion du ML, la pression du ballonnet et la pression inspiratoire ont été mesurées. On a demandé aux patients de coter le mal de gorge, la dysphonie ou la dysphagie comme absent, minimal, modéré ou sévère, immédiatement après, deux heures et 24 h après l'opération. Les données continues et catégorielles ont été comparées au moyen du test $t$ et du $\mathrm{Chi}^{2}$, respectivement.

From the Department of Anesthesiology, Neuromuscular Research Group (NRG), Centre Hospitalier de l'Université de Montréal (CHUM) Hôtel-Dieu, Université de Montréal, ${ }^{*}$ Montréal, Québec, Canada; and the Department of Anesthesiology, Friedrich-Alexander University, $†$ Erlangen, Germany.

Address correspondence to: Dr. T. M. Hemmerling, Department of Anesthesiology, Université de Montréal, Hôtel-Dieu, 3840 St.

Urbain, Montréal, Québec H2W 1T8, Canada. Phone: 514-890-8000, ext. 14570; Fax: 514-412-7222;

E-mail: thomashemmerling@hotmail.com

This work was performed using departmental internal funds.

Accepted for publication December 10, 2003.

Revision accepted April 12, 2004. 
Résultats : Les groupes NOBLOCK et BLOCK comportaient 68 et 62 patients. L'insertion du ML réussie au premier essai a été de $89 \%$ et de $92 \%$ dans les groupes NOBLOCK et BLOCK, respectivement. La moyenne des pressions intraballonnet et inspiratoire a été de $85 \pm 35$ $\mathrm{mmHg}$ et de $13 \pm 3 \mathrm{mmHg}$ pour les patients du groupe NOBLOCK, de $96 \pm 34 \mathrm{mmHg}$ et de $15 \pm 2 \mathrm{mmHg}$ pour ceux du BLOCK. L'incidence et la sévérité du mal de gorge, de la dysphonie et de la dysphagie ont été similaires dans les deux groupes, que ce soit immédiatement, deux ou 24 h après l'opération.

Conclusion : Le blocage neuromusculaire n'influence pas la facilité ou le taux de succès de l'insertion du ML, ni l'incidence et la sévérité de l'inconfort pharyngo-laryngé suivant l'utilisation de la ventilation à pression positive avec un ML.

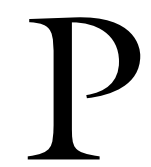

HARYNGOLARYNGEAL discomfort is a common cause of patient dissatisfaction after surgery and affects patients after hospital discharge. Sore throat, dysphagia, and dysphonia have been noted to occur less frequently after the use of a laryngeal mask airway (LMA) compared to endotracheal tubes (ETT). ${ }^{1}$ In a prospective study of more than 17,000 patients, Higgins et al. reported an incidence of sore throat after general anesthesia of $46 \%$ using ETT $v \boldsymbol{s}$ an incidence of $18 \%$ using a LMA. ${ }^{2}$ The difference in incidence of pharyngolaryngeal discomfort between ETT and LMA is one of the main arguments for the use of the LMA. Whereas initially the LMA was used mostly during "light" general anesthesia and spontaneous ventilation, a recent survey in the United Kingdom revealed that $44 \%$ of patients underwent positive pressure ventilation using the LMA. ${ }^{3}$ In the aforementioned study by Higgins et al., no remark is made regarding the mode of ventilation in patients who received a LMA. $^{2}$ However, Figueredo et al. showed that the incidence of dysphonia after general anesthesia using a LMA with positive pressure ventilation was significantly higher than with spontaneous ventilation. ${ }^{4}$ They hypothesized that the air flow during positive pressure ventilation might cause involuntary vibration and irritation of the unparalyzed vocal cords and result in postoperative dysphonia. We designed a prospective study to find out whether neuromuscular blockade of the vocal cords has an influence on the incidence of dysphonia after general anesthesia using a LMA with positive pressure ventilation.

\section{Methods}

This was a prospective, randomized, double-blind, two-centre prospective study. Ethical Committee approval and informed consent was obtained for all patients.
Patients, ASA physical status class I to III, who were undergoing surgery in the supine position with general anesthesia and a LMA were eligible. Patients less than $18 \mathrm{yr}$ of age, a history of cervical spine disease, or a known difficult airway, risk factors for aspiration, or undergoing abdominal or thoracic surgery were excluded. Patients were randomized to positive pressure ventilation with (BLOCK) or without complete neuromuscular blockade (NOBLOCK).

After preoxygenation with $100 \%$ oxygen via a face mask, general anesthesia was induced intravenously with remifentanil 0.25 to $0.5 \mu \mathrm{g} \cdot \mathrm{kg}^{-1} \cdot \mathrm{min}^{-1}$ followed by propofol $2.5 \mathrm{mg} \cdot \mathrm{kg}^{-1}$. According to group assignment, patients received either $0.1 \mathrm{mg} \cdot \mathrm{kg}^{-1}$ cisatracurium or the equivalent volume of $0.9 \%$ normal saline injected after loss of eye lash reflex. Five anesthesiologists each with over 500 previous LMA insertions, performed the LMA insertions in this study. The anesthesiologist who performed the insertion was blinded to the patient's allocation. A size 4 LMA (LMA-Classic ${ }^{\mathrm{TM}}$, Laryngeal Mask Company, Henley on Thames, UK) inflated with $30 \mathrm{~mL}$ of air and a size 5 LMA inflated with $35 \mathrm{~mL}$ of air were used for female and male patients, respectively. The number of attempts to insert the LMA was noted and the ease of insertion was graded $(1=$ easy, $2=$ moderately difficult, 3 = difficult, 4 = impossible). An alternative airway was used if the LMA could not be inserted after three attempts. The LMA was fixed according to the manufacturer's instructions. Criteria for an effective airway were a mean inspiratory pressure below $20 \mathrm{mmHg}$, no audible leakage, and no loss in expiratory volume.

Anesthesia was maintained by a remifentanil $i v$ infusion of 0.1 to $0.25 \mu \mathrm{g} \cdot \mathrm{kg}^{-1} \cdot \mathrm{min}^{-1}$ and sevoflurane at 1 to 1.5 minimum alveolar concentration in $30 \%$ oxygen and $70 \%$ air. Patients were ventilated with 6 $\mathrm{mL} \cdot \mathrm{kg}^{-1}$ tidal volume at a respiratory rate of $15 \cdot \mathrm{min}^{-1}$ to maintain a $\mathrm{PETCO}_{2}$ of 30 to $40 \mathrm{mmHg}$ at an inspiratory/expiratory ratio of $1: 1$ and a fresh gas flow of $2 \mathrm{~L} \cdot \mathrm{min}^{-1}$. In order to maintain the limits of $\mathrm{PETCO}_{2}$, only the tidal volume was increased or decreased. Intra-cuff pressure and inspiratory pressure were recorded every 15 min as well as the expiratory volume percent of sevoflurane and the infusion rate of remifentanil.

Neuromuscular monitoring was achieved by visual estimation of train-of-four (TOF) response of the corrugator supercilii muscle ${ }^{5}$ (TOF stimulation every 12 sec using routine electrocardiographic electrodes placed on the side of the eye, stimulation current of 30 $\mathrm{mA}$ using a square impulse nerve stimulator, Innervator ${ }^{\circledR}$, Fisher Paykel, Auckland, New Zealand).

In the BLOCK group, complete neuromuscular blockade was achieved by increments of cisatracurium 
of 0.01 to $0.05 \mathrm{mg} \cdot \mathrm{kg}^{-1}$ to maintain no visual response of the corrugator supercilii with TOF stimulation. Cisatracurium was discontinued $20 \mathrm{~min}$ before the end of surgery to allow spontaneous recovery of neuromuscular transmission. At the end of surgery, neuromuscular monitoring was performed at the adductor pollicis muscle with routine TOF stimulation of the ulnar nerve and tactile examination of the response. Reversal was given according to the response whenever necessary to achieve a TOF ratio of more than 0.8 .

Fifteen minutes prior to the end of surgery, sevoflurane was stopped and morphine 3 to $5 \mathrm{mg}$ iv was injected. Remifentanil was discontinued at the end of surgery. The LMA was removed with the cuff inflated in the operating room in all patients when the patient was able to open the mouth to command. On arrival in the postanesthetic care unit, the mouth was inspected for any damage to the tongue, lips or teeth. Patients were questioned immediately, two hours, and $24 \mathrm{hr}$ after surgery to grade sore throat (constant pain independent of swallowing), dysphonia (difficulty and pain on speaking), and dysphagia (difficulty or pain provoked by swallowing) as absent, minimal, moderate or severe. This was done by an anesthesiologist blinded to the patient's allocation.

The study sample size was calculated to detect a $25 \%$ difference in dysphonia between the two groups based on a control event rate of $15 \%$, a type I error of $5 \%$ and a power of $90 \%{ }^{4}$ Results were reported as mean \pm standard deviation and proportions and percentages for continuous and categorical data, respectively. The $t$ test and Chi-square test were used to compare continuous and categorical data, respectively. A $P$ value less than 0.05 was considered statistically significant.

\section{Results}

One hundred and thirty patients were enrolled in this study. There were no significant differences between the groups with respect to demographic and surgical details (Table I). Cuff pressure and inspiratory pressure were not statistically different between the groups (Table II). Insertion of a LMA was successful in all patients with insertion rates on the first attempt of almost $90 \%$ in both groups (Table II). In no patient was a misplacement of LMA noted or repositioning necessary during surgery. There were no adverse respiratory events (aspiration, hypoxia, bronchospasm or airway obstruction) in any patient. The doses of sevoflurane and remifentanil were not significantly different between the groups, nor were the cumulative doses of morphine used in the operating room and the
TABLE I Demographical and surgical details by group

\begin{tabular}{lll}
\hline & $\begin{array}{l}\text { NOBLOCK } \\
(n=68)\end{array}$ & $\begin{array}{l}\text { BLOCK } \\
(n=62)\end{array}$ \\
\hline Age $(\mathrm{yr})^{*}$ & $44 \pm 12$ & $47 \pm 13$ \\
Weight $(\mathrm{kg})^{*}$ & $69 \pm 13$ & $65 \pm 15$ \\
Sex (male/female) & $12 / 56$ & $16 / 46$ \\
ASA (I/II/III) & $42 / 16 / 10$ & $46 / 10 / 6$ \\
$\begin{array}{l}\text { Duration of anesthesia (min)* } \\
\text { Type of surgery }\end{array}$ & $55 \pm 14$ & $58 \pm 12$ \\
$\quad$ & 12 & 14 \\
$\quad$ General surgery & 25 & 22 \\
$\quad$ Gynecologic surgery & 10 & 9 \\
$\quad$ Orologic surgery & 21 & 17 \\
\hline
\end{tabular}

*Values are expressed as means \pm standard deviations.

TABLE II Study results by group

\begin{tabular}{lll}
\hline & $\begin{array}{l}\text { NOBLOCK } \\
(n=68)\end{array}$ & $\begin{array}{l}\text { BLOCK } \\
(n=62)\end{array}$ \\
\hline $\begin{array}{l}\text { First attempt insertion (\%) } \\
\text { Ease of insertion (\%) }\end{array}$ & 89 & 92 \\
$\quad$ Grade 1 & 85 & 82 \\
$\quad$ Grade 2 & 4 & 10 \\
$\quad$ Grade 3 & 9 & 8 \\
$\quad$ Grade 4 & 0 & 0 \\
Intra-cuff pressure $(\mathrm{mmHg})^{*}$ & $85 \pm 25$ & $96 \pm 34$ \\
Inspiratory pressure $(\mathrm{mmHg})^{*}$ & $13 \pm 3$ & $15 \pm 2$ \\
Sevoflurane dose $(\mathrm{vol} \mathrm{\%} \mathrm{exp)*}$ & $1.2 \pm 0.5$ & $1.3 \pm 0.3$ \\
Remifentanil rate $\left(\mu \mathrm{gg} \cdot \mathrm{kg}^{-1} \cdot \mathrm{min}^{-1}\right)^{*}$ & $0.12 \pm 0.06$ & $0.15 \pm 0.07$ \\
Intraoperative morphine dose $(\mathrm{mg})^{*}$ & $4.5 \pm 0.3$ & $4.8 \pm 0.4$ \\
24 hr morphine dose $(\mathrm{mg})^{*}$ & $15 \pm 5$ & $17 \pm 8$ \\
\hline
\end{tabular}

*Values are expressed as means \pm standard deviations.

postanesthesia care unit (Table II). Damage to the lips were noted in $1 \%$ and $1.5 \%$ of patients in the NOBLOCK and BLOCK groups, respectively. No patient reported severe pharyngolaryngeal complaints and the incidence and severity of complaints were not significantly different between the two groups (Figure).

\section{Discussion}

Neuromuscular blockade does not change the incidence of sore throat, dysphagia or dysphonia when a LMA is used during positive pressure ventilation. The overall incidence of pharyngolaryngeal discomfort was low and no patient reported any severe discomfort immediately or within $24 \mathrm{hr}$ after surgery. We could not find any support for paralysis of the vocal cords (as indicated by complete neuromuscular blockade at the corrugator supercilii muscle) during positive pressure ventilation to avoid irritation of the vocal cords and 


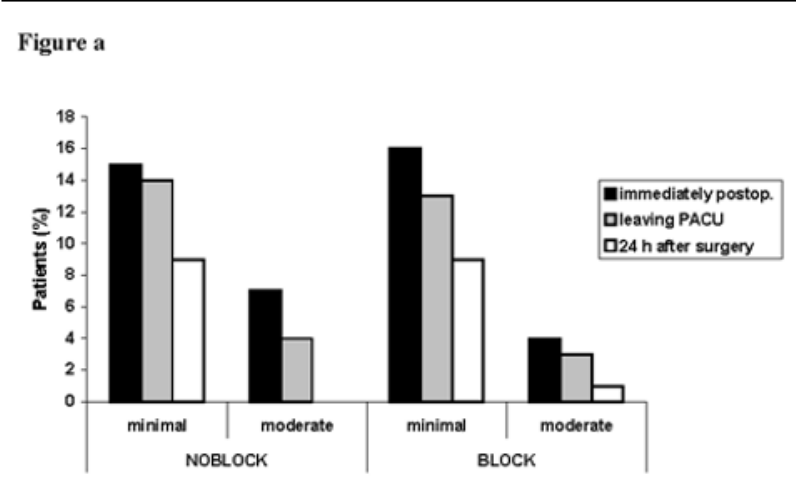

Figure b

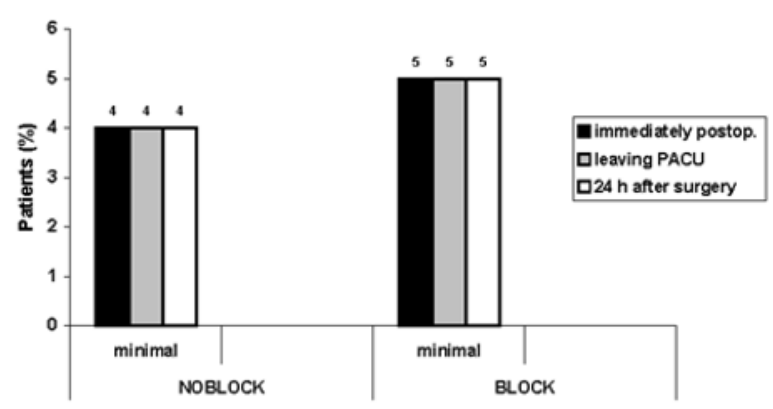

Figure c

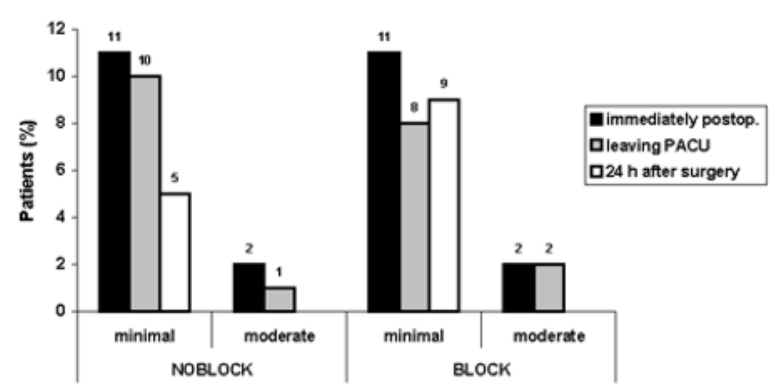

FIGURE Bar charts of the incidence and severity of (a) sore throat, (b) dysphonia, and (c) dysphagia in the NOBLOCK $(n=$ $68)$ and $\operatorname{BLOCK}(n=62)$ groups.

subsequent dysphonia. Neuromuscular blockade did not influence the ease of insertion or success rate of insertion of the LMA.

Direct measurement of laryngeal or pharyngeal neuromuscular blockade is not possible when a LMA is used. We therefore measured neuromuscular blockade at the corrugator supercilii muscle whose degree of neuromuscular blockade closely relates to neuromuscular blockade at the larynx. ${ }^{6}$ A high degree of neuromuscular blockade at the corrugator supercilii muscle equals an equally high degree of laryngeal block. In order to optimize the difference in neuromuscular blockade between the two groups, we opted for a complete blockade of the corrugator supercilii muscle (documented as no twitches with TOF stimulation) or no neuromuscular blockade at all. The absence of neuromuscular blockade did not influence the ease of positive pressure ventilation in our patients. No patient needed repositioning of the LMA or experienced air leakage during surgery. The chosen anesthetic regimen, sevoflurane and remifentanil, might have been a reason for the ease of positive pressure ventilation despite the absence of neuromuscular blockade in the NOBLOCK group. Remifentanil is known to facilitate even endotracheal intubation without the aid of neuromuscular blocking agents ${ }^{7,8}$ and its ability to profoundly block the nociceptive reaction could have helped to easily tolerate positive pressure ventilation. The chosen induction regimen of propofol $2.5 \mathrm{mg} \cdot \mathrm{kg}^{-1}$ two minutes after remifentanil infusion possibly created a sufficient depth of anesthesia for successful LMA insertion. ${ }^{9}$ Additional neuromuscular blockade did not alter the conditions of LMA insertion or the rate of success.

Our results compare reasonably well with a study that compared the incidence of sore throat after the use of LMA during controlled ventilation and spontaneous respiration. ${ }^{10}$ Cork et al. reported an incidence of about 20 to $30 \%$ of sore throat after the use of LMA during either type of ventilation; however, the study only evaluated sore throat, did not evaluate either dysphagia or dysphonia, and did not grade the symptoms. ${ }^{10}$ In addition, the total sample size was only 22 patients. The post hoc power analysis for our study showed that more than 6,000 patients would be required to demonstrate a statistically significant difference between our two groups.

Recently, the LMA-ProSeal ${ }^{\mathrm{TM}}$ (Laryngeal Mask Company, Henley on Thames, UK) has been advocated as a more suitable airway for positive pressure ventilation by providing a higher sealing pressure. ${ }^{11}$ Some studies have shown that in comparison to LMAClassic $^{\mathrm{TM}}$, the risk of gastric distension can be lowered. ${ }^{12}$ Cases have been published showing efficient prevention of aspiration with the LMA-ProSeal ${ }^{\mathrm{TM}} .^{13}$ However, it is too early to judge whether this has an influence on the suitability of this mask for positive pressure ventilation. The LMA-ProSeal ${ }^{\mathrm{TM}}$ is marketed especially as a device whose seal is designed to prevent higher inspiratory pressures thus providing a theoretical advantage over the LMA-Classic ${ }^{\mathrm{TM}}$ in positive pressure ventilation. In our study we used the LMA-Classic ${ }^{\mathrm{TM}}$ with a higher respiratory frequency to reduce the tidal volume and the inspiratory pressure. 
We measured no inspiratory pressure of more than 20 $\mathrm{mmHg}$ in any patient at any time. This might have been the reason for the absence of any clinical signs of gastric distension or misplacement of the LMAClassic $^{\mathrm{TM}}$. When different ventilator settings are used or higher inspiratory pressures occur, the LMAProSeal ${ }^{\mathrm{TM}}$ might be advantageous and provide better protection against gastric distension. ${ }^{11}$ Whether the higher sealing pressure of the LMA-ProSeal ${ }^{\mathrm{TM}}$ causes more pharyngolaryngeal discomfort than the LMAClassic $^{\mathrm{TM}}$ needs to be evaluated with further studies. In conclusion, neuromuscular blockade did not influence the incidence and severity of pharyngolaryngeal discomfort after positive pressure ventilation using a LMA-Classic ${ }^{\mathrm{TM}}$.

\section{References}

I McHardy FE, Chung F. Postoperative sore throat: cause, prevention and treatment. Anaesthesia 1999; 54: 444-53.

2 Higgins PP, Chung F, Mezei G. Postoperative sore throat after ambulatory surgery. Br J Anaesth 2002; 88: 582-4.

3 Verghese C, Brimacombe JR. Survey of laryngeal mask airway usage in 11,910 patients: safety and efficacy for conventional and nonconventional usage. Anesth Analg 1996; 82: 129-33.

4 Figueredo E, Vivar-Diago M, Munoz-Blanco F. Laryngo-pharyngeal complaints after use of the laryngeal mask airway. Can J Anesth 1999; 46: 220-5.

5 Le Corre F, Plaud B, Benhamou E, Debaene B. Visual estimation of onset time at the orbicularis oculi after five muscle relaxants: application to clinical monitoring of tracheal intubation. Anesth Analg 1999; 89: 1305-10.

6 Pland B, Debaene B, Donati F. The corrugator supercilii, not the orbicularis oculi, reflects rocuronium neuromuscular blockade at the laryngeal adductor muscles. Anesthesiology 2001; 95: 96-101.

7 Erban E, Ugur G, Alper I, Gunusen I, Ozyar B. Tracheal intubation without muscle relaxants: remifentanil or alfentanil in combination with propofol. Eur J Anaesthesiol 2003; 20: 37-43.

8 Durmus M, Ender G, Kadir BA, Nurcin G, Erdogan O, Ersoy $M O$. Remifentanil with thiopental for tracheal intubation without muscle relaxants. Anesth Analg 2003; 96: 1336-9.

9 Nakazawa K, Hikawa $\Upsilon$, Maeda M, et al. Laryngeal mask airway insertion using propofol without muscle relaxants: a comparative study of pretreatment with midazolam or fentanyl. Eur J Anaesthesiol 1999; 16: 550-5.

10 Cork RC, Depa RM, Standen JR. Prospective comparison of use of the laryngeal mask and endotracheal tube for ambulatory surgery. Anesth Analg 1994; 79: 719-27.

11 Brimacombe J, Keller C, Brimacombe L. A comparison of the laryngeal mask airway ProSeal and the laryngeal tube airway in paralyzed anesthetized adult patients undergoing pressure-controlled ventilation. Anesth Analg 2002; 95: 770-6.

12 Maltby JR, Beriault MT, Watson NC, Liepert D, Fick $G H$. The LMA-ProSeal is an effective alternative to tracheal intubation for laparoscopic cholecystectomy. Can J Anesth 2002; 49: 857-62.

13 Mark $D A$. Protection from aspiration with the LMAProSeal ${ }^{\mathrm{TM}}$ after vomiting: a case report. Can J Anesth 2003; 50: 78-80. 